\title{
Addressing the measurement of particulate organic and inorganic phosphorus in estuarine and coastal waters
}

\author{
Claire Labry*, Agnès Youenou, Daniel Delmas, Pascale Michelon
}

Ifremer Dyneco/Pelagos BP70, 29280 Plouzané, France

*: Corresponding author: Claire Labry, Tel.: +33298224914; fax: +33298224548;

email address : clabry@ifremer.fr

\begin{abstract}
:
The speciation of particulate phosphorus (TPP) into inorganic (PIP) and organic phosphorus (POP), has been scarcely investigated in suspended particulate matter (SPM), contrary to numerous sediment studies. This work evaluates the actual capacity of methods for TPP, POP and PIP determination in SPM to measure efficiently and specifically each pool. Methods were tested on a range of planktonassociated organic and inorganic $\mathrm{P}$ compounds, on microalgal cultures and estuarine samples. Then results are specifically discussed reviewing $P$ speciation in phytoplankton. For TPP analysis, the method of Solórzano and Sharp (1980) is recommended compared with that of Aspila et al. (1976), originally dedicated to sediment, as there is one step less, the protocol is more explicit (use of $\mathrm{MgSO}_{4}$ ) and it provides the best results. The application of the original protocol of the Aspila method for TPP (no $\mathrm{MgSO}_{4}$ ) results in underestimated and highly variable values. For POP, the CWO (Chemical Wet Oxidation) method tested here succeeds in providing sufficient oxidation of organic $P$, but, inorganic polyphosphate is yet too significantly hydrolysed, and intracellular phosphate, an underestimated PIP fraction, contributes to the POP pool with this method. Finally the Aspila method for PIP is the best compromise in estimating the contribution of PIP to TPP and POP by difference. Even if particulate polyphosphate is only partially hydrolysed $(41-49 \%)$, intracellular phosphate is included and only a very low percentage of organic $P$, essentially nucleotidic $P$, is attacked. In any case, our findings show clear evidence of the necessity to fully describe the procedure when $\mathrm{P}$ speciation methods are used.
\end{abstract}

\section{Highlights}

We evaluate methods for the speciation of particulate phosphorus in waters. Inorganic and organic compounds, algal cultures and estuarine samples were tested. Results are specifically discussed reviewing $\mathrm{P}$ speciation in phytoplankton. - The choice of methods takes into account intracellular phosphate and polyphosphate. Our findings show clear evidence of the necessity to fully describe method procedure.

Keywords: Phosphorus ; Speciation ; Waters ; Phytoplankton ; HTC ; CWO 


\section{Introduction}

Phosphorus $(P)$ is a key nutrient for coastal marine primary production and the inflow of $P$ from rivers is by far the dominant source to the coastal areas (Ruttenberg, 2003). It is well known that most $\mathrm{P}$ carried by rivers - up to more than $90 \%$ - is associated with particulate matter (Meybeck, 1982). However few studies have paid attention to the nature of this particulate $P$, and more specifically to the $P$ composition of suspended particulate matter (SPM; Zwolsman 1994; Conley et al., 1995). Total particulate phosphorus (TPP) is composed of inorganic P (PIP) and organic P (POP). PIP occurs in mineral phases, adsorbed to particles (biotic and abiotic) and as intracellular storage $P$ forms i.e. phosphate, pyrophosphate, polyphosphate (Yoshimura et al., 2007). POP comprises P incorporated in living and detrital organic molecules such as phosphomonoesters and diesters, phosphonates, nucleotides.

Up to now, research into the speciation of particulate phosphorus (TPP) has mainly focused on sediments (Slomp et al., 1998; Fang et al., 2007; Andrieux et al., 2008). In these studies, POP is routinely determined by the difference between TPP and PIP. TPP is measured by the High Temperature Combustion (HTC) / acid hydrolysis method of Aspila et al. (1976) and PIP by the single acid hydrolysis step. More complex sequential extraction schemes have also been widely used (Ruttenberg, 1992, Ruttenberg et al., 2009; Gleyzes et al., 2002). POP is generally extracted at the final step, with a strong extractant, and after all the extractions of inorganic $\mathrm{P}$ forms have been performed. The POP fraction is there considered to be refractory organic $\mathrm{P}$ (Worsfold et al., 2008).

Some studies on the speciation of TPP in coastal and estuarine waters have used the Aspila method (Yuan et al., 2009; Nemery and Garnier, 2007; Benitez-Nelson et al., 2004; Loh and Bauer, 2000). However the use of this method for SPM has not been discussed with regard to the different nature of SPM compared to particulate matter present in sediments. SPM contains more labile and soluble organic components than organic $P$ in sediment, which is likely to be more refractory. In addition, the protocol, which must be adapted to SPM collected on filters, is rarely detailed and different adaptations have been used. Although, the original protocol did not include the addition of an oxidant before the combustion process, some studies used one, such as $\mathrm{Mg}\left(\mathrm{NO}_{3}\right)_{2}$ (Ruttenberg, 1990, 1992, Suzumura, 2008). Solorzano and Sharp (1980) recommend the addition of $\mathrm{MgSO}_{4}$ before ignition for a similar HTC / hydrolysis method. In addition, alternative studies used the HTC method of Solorzano and Sharp for TPP and the Aspila method for PIP (Yoshimura et al., 2007). Others overlapped the Aspila and Solorzano and Sharp protocols for TPP (Suzumura et al., 2004; Van der Zee and Chou, 2005; Van der Zee et al., 2007). Therefore methods differing from the original protocols have been used but have not often been detailed and tested for their efficiency and specificity toward inorganic and organic $\mathrm{P}$ forms.

Similarly, methods used to separate PIP and POP are not clearly identified. For the determination of POP, some authors recommend persulfate chemical wet oxidation (CWO, Pujo-Pay and Raimbault, 1994). However, several CWO procedures exist, differing in $\mathrm{pH}$, persulfate concentration and in the addition of a buffer (Koroleff et al., 1983; Pujo-Pay and Raimbault, 1994; Raimbault et al., 1999). According to the concentration of the digestion reagent and $\mathrm{pH}$ of the reaction, inorganic $\mathrm{P}$ compounds may be hydrolysed (Suzumura, 2008). Different CWO versions may therefore analyse different particulate pools by including different contributions of inorganic $P$.

Conversely, it is generally assumed that the acid hydrolysis step used to determine PIP by the Aspila et al. (1976) method probably attacks a significant part of acid-labile organic $P$ compounds, leading to an overestimation of PIP and an underestimation of POP (Worsfold et al., 2008). However, to our knowledge, this interference of organic $P$ compounds on PIP has 
not been evaluated on a selection of pure P compounds. Instead, Ruttenberg $(1990,1992)$ tested the acid hydrolysis step on TPP in fresh and aged phytoplankton and found that $51 \%$ and $80 \%$ of the TPP, respectively, were removed by the acid extract. Actually, the consequences of this interference may be more important for POP in waters than for POP in sediment that's why a more precise distinction between inorganic and organic $P$ pools should be carried out.

The purpose of this study is to evaluate the actual capacity of methods for TPP, POP and PIP determination to measure efficiently and specifically each pool. All methods were tested on a large selection of organic and inorganic $P$ compounds in conditions for the measurement of particulate $\mathrm{P}$ in waters. Purely geochemical inorganic $\mathrm{P}$ compounds were not tested in this study, as was done elsewhere (Ruttenberg, 1992; Suzumura, 2008). Instead, biological associated P compounds were analysed such as inorganic condensed $P$ (i.e. pyrophosphate, polyphosphate), organic condensed $P$ (i.e. ATP), and organic P (i.e. phosphomonoesters and diesters, phosphonate). For POP determination, a new version of the CWO method modified from Raimbault et al. (1999) so as to be alkaline all through the reaction, was tested. This study brings new insights via experiments on phytoplankton cultures, field samples from estuarine waters discharging into the Bay of Brest as well as a review of plankton $\mathrm{P}$ composition.

\section{Material and methods}

Methods for particulate $P$ measurement were firstly tested on a range of organic $P$ and inorganic $\mathrm{P}$ compounds, after which they were applied on filter-collected material from algal cultures and field samples (Aulne estuarine waters, Bay of Brest, France).

\subsection{From a range of $P$ compounds to algal cultures and field samples}

\subsection{1. $\mathrm{P}$ compounds}

A selection of naturally occurring $P$ compounds was made according to the type of $P$ bonds (Table 1), one phosphonate (C-P, AEPA); eight phosphomonoesters (C-O-P) including 3 phosphosugars (GP, GluP, RP), one phospholipid (PCC), one nucleotide (AMP), two metabolic intermediate compounds (RMP, PEPA) and one phosphoric acid (PA); one phosphodiester (C-O-P-O-C, DNA); two nucleotides including phosphomonoester and phosphoric anhydride bonds (C-O-P-O-P, ADP, ATP) and five inorganic polyphosphate (P-O$P$ ) including three straight chain compounds (PP, TP, polyP- $n$ ) and two ring chain compounds (MP, HP). The compounds were stored as specified by the manufacturer. They were dried in a $50{ }^{\circ} \mathrm{C}$ oven for $12 \mathrm{~h}$ before use, thus avoiding thermal decomposition at higher temperature. The compounds were dissolved in distilled high purity Milli-Q deionized water (DIW) to obtain gravimetrically concentrations of $500 \mu \mathrm{mol} / \mathrm{P}$ P. A standard solution of $500 \mu \mathrm{mol} / / \mathrm{PO}_{4}$ was prepared to follow the same procedures as the organic and inorganic $\mathrm{P}$ solutions. The solution of $500 \mu \mathrm{mol} / \mathrm{l}$ P-DNA was prepared from salmon testes DNA. The $\%$ weight $P$ (10.0) was estimated from the \% G-C reported by the manufacturer (41.2). A $200 \mu \mathrm{l}$ subsample of each solution was treated, corresponding to 1.3 to $6.7 \mu \mathrm{mol} / \mathrm{l}$ of $\mathrm{P}$ to be measured in the final solution depending on the extract volume, dilution factor and assuming $100 \%$ recovery. Some $\mathrm{P}$ compounds may hydrolyse during the final acidic phosphomolybdate-blue reaction used to quantify phosphate (Murphy and Riley, 1962). In order to estimate this molybdate-reactive $P$ fraction, usually referred to as "soluble reactive phosphorus" (SRP), and potential phosphate contamination, all standard solutions were analysed for phosphate prior to oxidation by diluting $200 \mu \mathrm{l}$ in $20 \mathrm{ml}$ DIW. Blanks including DIW and reagents were determined by following the same procedure as for the $\mathrm{P}$ solutions. 
For each tested method, a normalized recovery was calculated using the ash/hydrolysis method of Solorzano and Sharp (1980), which usually gives the best oxidation efficiency. It is the best way to overcome problems due to purity and hygroscopic nature of some compounds (Kerouel and Aminot, 1996). The replicability errors were calculated over triplicates.

\subsection{2. $\mathrm{P}$ collected on filters}

Some samples were prepared from batch cultures of Alexandrium minutum (AM89BM strain). The dinoflagellate was grown in $\mathrm{f} / 2$ medium (Guillard and Ryther, 1962) in sterilized natural seawater at $18{ }^{\circ} \mathrm{C}$ with a $12: 12 \mathrm{~h}$ photoperiod. Replicates of $10 \mathrm{ml}$ cultures were subsampled in mid exponential phase at 10910 cells / ml and filtered on precombusted (480 ${ }^{\circ} \mathrm{C}$ for $2 \mathrm{~h}$ ) glass fiber filters (Whatman GF/F, $25 \mathrm{~mm}$ ). Seawater samples from the Aulne estuary were collected at 17 salinity in autumn 2010. Replicates of $80 \mathrm{ml}$ samples were filtered on precombusted $\left(480{ }^{\circ} \mathrm{C}\right.$ for $2 \mathrm{~h}$ ) glass fiber filters (Whatman GF/F, $25 \mathrm{~mm}$ ). All filters were deep frozen $\left(-20^{\circ} \mathrm{C}\right.$ ). Procedural blanks (DIW + reagent + GF/F filter) were determined by laying the filters on the filtration system and following the same protocol as algal or field samples collected on filters. The replicability errors were calculated over five replicates. All PP concentration data presented are blank-subtracted.

\subsubsection{Cleaning procedures}

All borosilicate vials were soaked with phosphate free detergent then with $1 \% \mathrm{vol} / \mathrm{vol}$ sulfuric acid and finally rinsed with DIW.

\subsection{Particulate phosphorus methods}

Five methods were tested, three methods regarding the measurement of TPP, one for the measurement of PIP and one for the determination of POP (Figure 1). Since all methods consist in converting forms of combined $P$ into phosphate, the subsequent quantification of phosphate was achieved by the phosphomolybdate-blue colorimetric reaction (Murphy and Riley, 1962) using segmented flow analysis (Aminot et al., 2009).

\subsubsection{TPP methods}

Three methods are aimed at measuring TPP (Figure 1) : (1) the method of Solorzano and Sharp (1980) referred to, in the text, as the "Ash/0.2 M HCl" method, (2) the procedure of Aspila et al. (1976) modified by the addition of $\mathrm{MgSO}_{4}$, as an oxidant before the ashing step, named hereafter the "Ash/1 M HCl" method, and (3) the original procedure of Aspila et al. (1976) referred to as the "Ash/1 $\mathrm{M} \mathrm{HCl} \mathrm{No} \mathrm{MgSO}_{4}$ " method.

\subsubsection{The "Ash/0.2 M HCl" method}

Either filters or $200 \mu \mathrm{l}$ compound solutions placed in a borosilicate vial were dried with $2 \mathrm{ml}$ of $0.017 \mathrm{~mol} / \mathrm{l} \mathrm{MgSO}$ in a $95{ }^{\circ} \mathrm{C}$ oven for $3 \mathrm{~h}$, then ashed at $480{ }^{\circ} \mathrm{C}$ for $2 \mathrm{~h}$. After cooling, they were acid-hydrolysed in $5 \mathrm{ml}$ of $0.2 \mathrm{~mol} / \mathrm{l} \mathrm{HCl}$ in an $80{ }^{\circ} \mathrm{C}$ oven for $30 \mathrm{~min}$. Unlike the evaporation step, the baking and hydrolysis steps were done with tightly fitted lids. $10 \mathrm{ml}$ DIW was added and the vials were centrifuged at $3000 \mathrm{rpm}$ for $5 \mathrm{~min}$ before phosphate measurement on supernatants. 


\subsubsection{The "Ash/1 M HCl" method}

The method was adapted on the basis of the Solorzano and Sharp (1980) procedure by introducing $\mathrm{MgSO}_{4}$ before the combustion step. Filters or $200 \mu \mathrm{P}$ compound solutions placed in a borosilicate vial were dried with $2 \mathrm{ml}$ of $0.017 \mathrm{~mol} / / \mathrm{MgSO}_{4}$ in a $95{ }^{\circ} \mathrm{C}$ oven for 3 $\mathrm{h}$, then ashed at $550{ }^{\circ} \mathrm{C}$ for $2 \mathrm{~h}$. After cooling, they were acid-hydrolysed in $5 \mathrm{ml}$ of $1 \mathrm{~mol} / \mathrm{l}$ $\mathrm{HCl}$ at ambient temperature for $18 \mathrm{~h} .10 \mathrm{ml}$ DIW was added and the vials were centrifuged at $3000 \mathrm{rpm}$ for $5 \mathrm{~min}$. Because the development of the phosphomolybdate-blue complex is slowed down by excess acidic conditions (Aminot and Kerouel, 2004, 2007), the phosphate was analysed on five-fold diluted supernatants.

\subsubsection{The "Ash/1 $\mathrm{M} \mathrm{HCl} \mathrm{No} \mathrm{MgSO}_{4}$ " method}

In contrast with the Ash/1 $\mathrm{M} \mathrm{HCl}$ method, $\mathrm{MgSO}_{4}$ was not introduced before the combustion step, as in the original Aspila et al. (1976) procedure. Apart from the addition of $\mathrm{MgSO}_{4}$, the procedure is identical to that described in $\S 2.2 .1 .2$.

\subsubsection{The POP method}

The CWO method tested for the determination of POP was a persulfate oxidation method carried out in alkaline conditions throughout the reaction. The method consisted in oxidizing organic $\mathrm{P}$ by the action of persulfate reagent at $120{ }^{\circ} \mathrm{C}$ under alkaline buffered conditions. The oxidizing reagent composition was according to Raimbault et al. (1999). It was composed of $30 \mathrm{~g}$ disodium tetraborate dissolved in $250 \mathrm{ml} \mathrm{DIW}$ heated at 40 to $50{ }^{\circ} \mathrm{C}$, then submitted to an addition of $15 \mathrm{~g}$ potassium peroxodisulfate $\left(\mathrm{K}_{2} \mathrm{~S}_{2} \mathrm{O}_{8}\right)$. The procedure used here excluded the acidification step introduced by Raimbault and co-authors before oxidation. This step associated with bubbling was dedicated to remove inorganic carbon transformed into carbon dioxide, for the subsequent simultaneous measurement of particulate organic carbon and phosphorus. Since this step reduces $\mathrm{pH}$ to 2.5, a part of the inorganic phosphorus could be hydrolysed, which is precisely what we wished to avoid in our study. The procedure was as follows: filters or $200 \mu \mathrm{P}$ compound solutions were placed in flasks with $20 \mathrm{ml}$ of DIW and $2.5 \mathrm{ml}$ of reagent. The flasks were autoclaved at $120{ }^{\circ} \mathrm{C}$ for 30 min. Initial $\mathrm{pH}$ was 9.3 and $\mathrm{pH}$ remained alkaline (8.2) after digestion. The vials were centrifuged at $3000 \mathrm{rpm}$ for $5 \mathrm{~min}$ before phosphate measurement on supernatants.

\subsection{The PIP method}

The procedure tested for the determination of PIP was that of Aspila et al. (1976), named as the " $1 \mathrm{M} \mathrm{HCl}$ » method. Either filters or $200 \mu \mathrm{l}$ compound solutions placed in a borosilicate vial were dried in a $50{ }^{\circ} \mathrm{C}$ oven for $3 \mathrm{~h}$. To avoid the decomposition of organic $\mathrm{P}$ compounds on heating, the dry temperature was chosen to be $50^{\circ} \mathrm{C}$ instead of $95^{\circ} \mathrm{C}$. The samples were then acid-hydrolysed in $5 \mathrm{ml}$ of $1 \mathrm{~mol} / \mathrm{l} \mathrm{HCl}$ at ambient temperature for $18 \mathrm{~h}$. $10 \mathrm{ml}$ DIW was added and the vials were centrifuged at $3000 \mathrm{rpm}$ for $5 \mathrm{~min}$. The phosphate was analysed on five-fold diluted supernatants.

\section{Results}

\subsection{Experimental controls}

Experimental controls consisted in blank determination, a recovery test with a phosphate standard solution and potential contamination or decomposition of $\mathrm{P}$ compound solution. 


\subsubsection{Blank determination}

Procedural blanks (DIW + reagent + GF/F) in both HTC/hydrolysis methods are slightly lower $(0.001 \mu \mathrm{mol}$ per filter) than those found by Suzumura (2008) for a mixed version of Aspila and Solorzano and Sharp protocols $(0.002 \mu \mathrm{mol}$ per filter). However procedural blanks in the CWO method $(0.004 \mu \mathrm{mol}$ per filter) are significantly higher than those in HTC/hydrolysis methods $(p<0.001$, Mann and Whitney test). They are slightly higher than those found in Raimbault et al. (1999) protocol for the same filter (0.002 to $0.003 \mu \mathrm{mol}$ per filter). Suzumura (2008) found a considerably lower value $(0.0008 \mu \mathrm{mol}$ per filter). The difference is largely due to a contamination of the oxidizing reagent since DIW + GF/F blanks evaluated without the oxidizing reagent (results not figured) gave only $0.0005 \pm 0.0002 \mu \mathrm{mol}$ per filter $(n=10)$. The use of a highly pure low- $\mathrm{P} \mathrm{K}_{2} \mathrm{~S}_{2} \mathrm{O}_{8}$ would probably result in a reduction of procedural blanks. However, in any case, blanks are negligible compared with samples.

\subsubsection{Recovery test with a phosphate standard solution}

For $\mathrm{P}$ compound analyses, a standard solution of $\mathrm{PO}_{4}$ submitted to the same procedures as the $\mathrm{P}$ compound solutions was tested to ensure that the comparison of methods would be free of biased errors such as the effect of extract $\mathrm{pH}$ on the phosphomolybdate-blue reaction, potential evaporation, reagent dilution and so forth. Recovery data were calculated on the basis of the $\mathrm{PO}_{4}$ theoretical concentration corrected for manufacturer's purity (Table 2). The difference in recovery values between methods lay within a $0-3 \%$ range. They were not significantly different $(p<0.001$, Mann and Whitney test).

\subsubsection{Analysis of $P$ compound solutions for phosphate}

P compound solutions were analysed for phosphate prior to oxidation. Their potential response in phosphate may emphasize their tendency to hydrolyse spontaneously or during the phosphomolybdate-blue reaction ( $\mathrm{pH} \mathrm{0.8,} \mathrm{Aminot} \mathrm{et} \mathrm{al.,} \mathrm{2009)} \mathrm{in} \mathrm{addition} \mathrm{to} \mathrm{a} \mathrm{potential}$ $\mathrm{PO}_{4}$ contamination. Out of the seventeen compounds tested, nine yielded less than $0.5 \%$ phosphate (Table 3 ) and the rest ranged within values < $4.6 \%$ apart from polyP- $n(9.9)$. Similar low levels were found by Thomson-Bulldis and Karl (1998) and Monaghan and Ruttenberg (1999). The differences in responses found between various authors for the same compounds depend largely on phosphate impurities and on the actual reaction conditions which are slightly different if the method is manual (longer contact time of sample and reagents) or automated (shorter contact time). Only a very small fraction of $P$ compounds is detected as phosphate before oxidation using the segmented flow analysis of phosphate (Aminot et al., 2009).

\subsection{TPP methods}

For $\mathrm{P}$ compound solutions, $\mathrm{P}$ recoveries by the "Ash/1 $\mathrm{M} \mathrm{HCl}$ " method ranged between 97 and $102 \%$ (Table 3). Relative standard deviations for all compounds were lower for "Ash/0.2 $\mathrm{M} \mathrm{HCl}$ " than for "Ash/1 $\mathrm{M} \mathrm{HCl",} 0.3 \%$ and $1.4 \%$ on average respectively. The slight difference in recovery and reproducibility between the "Ash/1 $\mathrm{M} \mathrm{HCl}$ " and the "Ash/0.2 M $\mathrm{HCl}$ " methods is attributed to experimental errors since the former method includes an additional dilution step. However, by not adding $\mathrm{MgSO}_{4}$ as in the original protocol of Aspila et al (1976), $\mathrm{P}$ recoveries fell between 33 to $65 \%$ and were highly variable, the relative standard deviation averaging $9.6 \%$ (5.6\% without the highest value for AEPA).

For $\mathrm{P}$ collected on filters, particulate $\mathrm{P}$ values obtained by the "Ash/1 M HCl" method represented $97 \%$ and $95 \%$ of those obtained by "Ash/0.2 M HCl" for $A$. minutum cultures and for SPM of the Aulne estuary respectively (significant difference, $p<0.025$ and $p<$ 
0.001 , Mann and Whitney test, Table 4). The lack of $\mathrm{MgSO}_{4}$ led to significantly lower values for algal cultures ( $p<0.001$, Mann and Whitney test). The difference is lower for Aulne estuary samples.

\subsection{The POP method}

For $\mathrm{P}$ compound analyses, the CWO method displayed contrasting results depending on the type of $P$ bond (Table 3). High recoveries $(100-103 \%)$ were obtained for all phosphomonoesters containing C-O-P bonds, for phosphodiester (C-O-P-O-C, DNA) and for phosphonate (C-P, AEPA). Lower recoveries were obtained for nucleotides (26- $29 \%$ ) containing both phosphomonoester and phosphoric anhydride bonds. Inorganic polyphosphate responded differently to the CWO treatment. MP was almost not hydrolysed (3 \%) and TP was the most attacked (47\%). Relative standard deviations for all compounds were low $(0.8 \%$ on average, Table 3$)$. For $\mathrm{P}$ collected on filters, the CWO method displayed highly significant lower values than both $\mathrm{HTC}$ /hydrolysis methods, representing 79 and $64 \%$ of those obtained by the "Ash/0.2 M HCl" method for $A$. minutum cultures and for SPM of the Aulne estuary, respectively (Table 4).

\subsection{The PIP method}

For $\mathrm{P}$ compound analyses, the hydrolysis of $\mathrm{P}$ organic compounds during the PIP determination by the Aspila method was specifically estimated. Statistically significant responses were found in nine out of the twelve organic compounds, comparing the results after the $1 \mathrm{M} \mathrm{HCl}$ treatment and the responses as phosphate $(p<0.001$, Mann and Whitney test, Table 3). However, for most phosphomonoesters, the difference in hydrolysis between 1 $\mathrm{M} \mathrm{HCl}$ and the phosphomolybdate blue reaction is $<1 \%$. This difference ranged between 1 and $2 \%$ for AEPA, PA and PCC, and reached $9.4 \%$ for PEPA. On the other hand, organic P compounds containing P-O-P bonds i.e. ADP and ATP showed relatively high hydrolysis by the $1 \mathrm{M} \mathrm{HCl}$ treatment, up to $10 \%$ and $24 \%$ respectively. Concerning $\mathrm{P}$ inorganic compounds, hydrolysis reached 41 to $49 \%$ for polyphosphate, which is far from the $100 \%$ expected. Regarding P collected on filters, the " $1 \mathrm{M} \mathrm{HCl}$ " method hydrolysed $40 \%$ and $60 \%$ of TPP for A. minutum cultures and for SPM of the Aulne estuary respectively (Table 4).

\section{Discussion}

Particulate $\mathrm{P}$ is, by far, the dominant $\mathrm{P}$ pool brought by rivers to the estuarine and coastal areas (Meybeck, 1982). However, little is known about its chemical composition, even though the bioavailability of its components for phytoplankton is a crucial point when attempting to understand the dynamics of coastal primary production. The first step for $\mathrm{P}$ speciation is to estimate inorganic and organic pools, even though each pool itself represents various $P$ forms of different reactivities, both geochemically and biologically (Ruttenberg, 2003). POP comprises $P$ incorporated in living and detrital organic molecules such as phosphomonoesters, phosphodiesters, phosphonates, nucleotides (Figure 2). PIP occurs linked to both abiotic and biotic particles. Inorganic $\mathrm{P}$ is either adsorbed to abiotic and biotic particles or included in mineral phases or it represents intracellular storage $P$ forms i.e. phosphate, pyrophosphate, polyphosphate (Figure 2). This latter fraction, PIP as intracellular $\mathrm{P}$ storage compounds, is usually ignored by $\mathrm{P}$ speciation studies. The measurement of PIP included in so different particles such as mineral and biotic particles is an analytical challenge. By testing a large range of $\mathrm{P}$ compounds, biotic particles such as phytoplankton cells, and abiotic and biotic estuarine particles, the present study discusses the limitations of the chemical methods in definitively separating POP and PIP forms. 


\subsection{Comparison of TPP methods}

As underlined by others (Kerouel and Aminot, 1996; Suzumura, 2008), the use of a reference method for recovery assessment and comparison between methods is the best way to avoid problems such as purity, hygroscopic nature, UV sensitivity of some compounds and so forth. As an example, the manufacturer (Sigma) does not certify DNA P quantity which is therefore estimated from the \% G-C reported for such salmon testes DNA. Recoveries regarding DNA cannot be calculated accurately. It is the same for polyP- $n$. The reference method used here is the HTC / hydrolysis method of Solorzano and Sharp (1980) since it provides almost the complete recovery of various compounds according to previous reports for both TDP and TPP (Kérouel and Aminot, 1996; Ormaza-Gonzalez and Statham, 1996; Monaghan and Ruttenberg, 1999).

The HTC/hydrolysis method of Aspila et al. (1976) provided high recoveries for all types of $\mathrm{P}$ bonds (97 to $102 \%$ ) and for field (95\%) and phytoplankton cultures (97\%), if the protocol included the use of an oxidant, here $\mathrm{MgSO}_{4}$. The slight differences found with the method of Solorzano and Sharp (1980) were attributed to experimental errors since the final dilution step necessary for the development of the phosphomolybdate-blue complex in Aspila et al (1976) may introduce errors. In field samples, complex compounds may be less hydrolysed by the Aspila method than that of Solorzano and Sharp (1980). However, since only one field sample was tested, this result cannot be generalized. With no addition of $\mathrm{MgSO}_{4}$ during the combustion process, only 33 to $65 \%$ of $\mathrm{P}$ in compounds tested was converted into phosphate and the results were less reproducible than those obtained with $\mathrm{MgSO}_{4}$. The difference in recovery obtained with or without the use of $\mathrm{MgSO}_{4}$ has not been tested previously for TPP determination. Testing TDP measurement, Solorzano and Sharp (1980) found variable and low recoveries of $P$ from organic and inorganic compounds (40-100\%) when $\mathrm{MgSO}_{4}$ was omitted. We did not test another oxidant in this study. However comparing the addition of $\mathrm{MgSO}_{4}$ or $\mathrm{Mg}\left(\mathrm{NO}_{3}\right)_{2}$ in the protocol for TDP, Monaghan and Ruttenberg (1999) found similar efficiencies for both oxidants. Obviously, our findings highlight the need to fully describe the procedure used when Aspila et al. (1976) is applied to SPM collected on filters. The use of the Solorzano and Sharp (1980) method for TPP in waters is recommended as there is one step less (no final dilution step), the protocol is more explicit (use of $\mathrm{MgSO}_{4}$ ) and the results are the best.

\subsection{The POP method}

In the present study, a CWO method was tested to obtain both the sufficient oxidation of organic $\mathrm{P}$ compounds and also a reduced hydrolysis of inorganic $\mathrm{P}$ molecules. The hydrolysis of polyphosphate is mainly affected by acidity, temperature and reaction time (Maher and Woo, 1998). Several versions of the persulfate CWO method include acid conditions of different strengths, thus the PIP forms in the final results are taken into account differently. In the acid CWO method of Koroleff et al. (1983), $\mathrm{K}_{2} \mathrm{~S}_{2} \mathrm{O}_{8}$ was initially dissolved in sulfuric acid. In Menzel and Corwin (1965) and in the particulate version of Pujo-Pay and Raimbault (1994), $\mathrm{pH}$ following oxidation became acid, $1.5-1.8$ and $1.7-2.3$ respectively, as a result of the decomposition of $\mathrm{K}_{2} \mathrm{~S}_{2} \mathrm{O}_{8}$ into sulfuric acid at high temperature. Valderrama (1981) and the alkaline CWO version of Koroleff (1983) obtained lower acid conditions, pH being 5-6 and 4-5 respectively, due to the buffer capacity of the boric-acid-sodium hydroxide system. In Raimbault et al. (1999), initial pH reached 2.5 due to the first acidification step dedicated to remove inorganic carbon for the subsequent simultaneous measurement of particulate organic carbon and phosphorus. This acidification step would probably hydrolyse inorganic $\mathrm{P}$ and this method would analyse rather TPP than POP only. However, since their oxidizing reagent included disodium tetraborate as a buffer to neutralize the production of $\mathrm{H}_{2} \mathrm{SO}_{4}, \mathrm{pH}$ at the beginning of digestion was alkaline (>9) and remained alkaline (8.2-8.5) 
after digestion. The method tested in the present study consists in removing the first acidification step in order to remain alkaline throughout the procedure, thus minimizing the hydrolysis of inorganic $P$ compounds. The results displayed high recoveries (100 - $103 \%)$ for all phosphomonoesters, phosphodiesters and phosphonate. On comparing the results of similar DIW-dissolved solutions of organic $\mathrm{P}$ compounds, our recoveries are as high as those obtained in the $3 \%(\mathrm{w} / \mathrm{v}) \mathrm{K}_{2} \mathrm{~S}_{2} \mathrm{O}_{8}$ CWO method of Suzumura (2008) and in the alkaline CWO of Koroleff (1983) used by Kerouel and Aminot (1996), $97-103 \%$ and $99-103 \%$ for all compounds tested (except $108 \%$ for AEPA), respectively. Suzumura (2008) attributed their high recoveries for organic $P$ compounds to the stronger concentration of the persulfate solution they used. Our study reports the same recoveries for a $0.67 \%(\mathrm{w} / \mathrm{v}) \mathrm{K}_{2} \mathrm{~S}_{2} \mathrm{O}_{8} \mathrm{CWO}$. The increase in $\mathrm{K}_{2} \mathrm{~S}_{2} \mathrm{O}_{8}$ concentration without the addition of buffer such as that used by Suzumura (2008) improves the hydrolysis of inorganic P compounds (P-O-P bonds) both by increasing the oxidation reagent and by decreasing $\mathrm{pH}$. Suzumura (2008) actually found 101 - $120 \%$ recoveries for four inorganic $P$ compounds containing linear or ring phosphoric anhydride bonds (P-O-P). In contrast, the present CWO method actually reduced the hydrolysis of inorganic $P$ compounds with a recovery range from 3 to $47 \%$. The alkaline version of Koroleff (1983) reported recoveries above $60 \%$ for condensed phosphate.

Thus this method succeeds in providing sufficient oxidation of organic $P$ compounds, even the most refractory compounds of the selection, AEPA, PA and PCC. However, di and triphosphate nucleotides are underestimated and, even if the hydrolysis of inorganic $P$ compounds is actually reduced compared with other CWO methods, it still reaches a significant value. Therefore this alkaline CWO version cannot definitively separate organic and inorganic compounds.

\subsection{The PIP method}

It is generally assumed that the $1 \mathrm{M} \mathrm{HCl}$ step used to determine PIP by the Aspila method probably attacks a significant part of the acid-labile organic $P$ compounds (Worsfold et al., 2008). However, to our knowledge, no studies have actually evaluated this attack on a selection of organic $\mathrm{P}$ compounds. Comparing the TPP measured in extracts resulting from different chemical treatments with aged plankton and fresh phytoplankton, Ruttenberg (1990, 1992) found that $1 \mathrm{M} \mathrm{HCl}$ extracted 0.17 over $0.34 \mathrm{wt} \% \mathrm{P}$, i.e. $51 \%$ of the TPP in fresh phytoplankton, and 0.23 over $0.29 \mathrm{wt} \%$ P, i.e. $80 \%$ of the TPP in aged plankton. This extracted TPP fraction was either hydrolized to phosphate by $1 \mathrm{M} \mathrm{HCl}$ or was initially in inorganic $\mathrm{P}$ forms in plankton or was just solubilized without hydrolysis. In all cases it should be evaluated so as to achieve a better understanding of the efficiency of the Aspila method when separating PIP and POP.

In the present study, when testing phosphomonoesters or diesters, the difference in hydrolysis between $1 \mathrm{M} \mathrm{HCl}$ and the phosphomolybdate blue reaction was $<2 \%$. The latter difference reached $9.4 \%$ for PEPA. This study confirms that a part of organic $\mathrm{P}$ compounds is hydrolysed during the PIP determination but this part remains small for major phosphomonoesters and diesters. This part increases for nucleotides di and triphosphate containing acid sensitive P-O-P bonds (ADP, ATP). Miyata et al. (1986) analysed the P composition of Skeletonema costatum and Heterosigma akashiwo under different cellular $\mathrm{P}: \mathrm{N}$ ratios and estimated that the nucleotidic $\mathrm{P}$ pool (mono, di and triphosphate) contributed to 3.5 to $9.2 \%$ of TPP in algae. This contribution ranged between 0.2 to $6.3 \%$ of TPP from natural plankton populations in Tokyo Bay waters (Miyata and Hattori, 1986). The nucleotidic labile P pool reached $21 \%$ in Scenedesmus sp. according to Rhee (1973). Finally, the Aspila method for PIP in samples containing significant phyto and bacterioplankton, hydrolyses only low percentages of intracellular organic $P$, essentially nucleotidic $P$. In the light of these results, high $P$ extraction results obtained by Ruttenberg $(1990,1992)$ could be interpreted 
either as a solubilization of organic $\mathrm{P}$ molecules from plankton, or as a major contribution of inorganic $P$ reserve forms to TPP in plankton.

\subsection{Toward a compromise in separating organic and inorganic phosphorus}

We tested two alternatives for the estimation of global organic and inorganic P: firstly, measuring directly PIP as phosphate after $1 \mathrm{M} \mathrm{HCl}$ extraction, and calculating POP as the difference between TPP and PIP, secondly, measuring directly POP after persulfate oxidation and calculating PIP as the difference between TPP and POP. Figure 3 illustrates the contribution of PIP and POP to TPP measured or calculated, according to the two alternatives, and applied to algal and field samples. The use of " $1 \mathrm{M} \mathrm{HCl}$ " extraction method for PIP leads to 19 to $24 \%$ higher contribution of PIP to TPP than the CWO method for POP (Figure 3).

This difference may come from a particularly high PIP contribution to TPP in the Aulne estuary and in $A$. minutum. When the " $1 \mathrm{M} \mathrm{HCl}$ " extraction method for PIP was used, the contribution of PIP to TPP in the Aulne estuary samples reached $60 \%$ (Figure 3). Further investigations in the Aulne estuary undertaken in February, May, July and November 2009 displayed a range of PIP contributions from 24 to $68 \%(50 \pm 9 \%, n=28$, Figure 4). These contributions are similar or lower than those found by Van der Zee et al. (2007) and Nemery and Garnier (2007) in the Scheldt and the Seine estuaries with similar methods, $65 \%$ and 66 - $75 \%$ respectively. They are even lower than those found when a sequential extraction of $P$ forms was used, 70 - $80 \%$ in the Gironde estuary (Deborde et al., 2007). Thus PIP contribution is not particularly high in the Aulne estuary.

In A. minutum cultures, PIP contribution to cellular $\mathrm{P}$ reached $40 \%$ with the "1 M HCl" method and $21 \%$ with the CWO method (Figure 3). It must be compared to the standard part of inorganic versus organic $\mathrm{P}$ forms in phytoplankton, schematically represented in Figure 2. Few studies have paid attention to the cellular $\mathrm{P}$ composition in microalgae. Miyata et al. (1986) used a chemical fractionation method to determine the P components in Skeletonema costatum and Heterosigma akashiwo. Even if their method may also contain biaised extractions of each $\mathrm{P}$ form, we added the inorganic $\mathrm{P}$ compounds (phosphate and polyphosphate) to constitute PIP and organic $P$ forms (nucleotidic $P$, nucleic acid $P$, sugar $P$, lipid $P$ and residual $P$ supposed to be phosphoproteins, Miyata and Hattori, 1986) to constitute POP. The PIP contribution ranged from 31 to $42 \%$ for S. costatum and from 20 to $59 \%$ for $\mathrm{H}$. akashiwo, along a nutritional gradient from $\mathrm{P}$ limitation to $\mathrm{N}$ limitation (Table 5). The PIP pool is lower when P limits algal growth. The natural populations of Tokyo Bay were analysed by the same method and were found to be made up of $45 \%$ PIP (Miyata and Hattori, 1986). These populations were not assumed to be nutrient limited. Thompson et al. (1994) found $19-20 \%$ of PIP for a cyanophycaea whatever the P status. On analysing by ${ }^{31} \mathrm{P}$ NMR a number of algal species cultured under different environmental stress, the study by Cade-Menun and Paytan (2010) led to a PIP contribution from 40 to $91 \%$ (Table 5). Even in $\mathrm{P}$ stress conditions, PIP still reached $47 \%$ of cellular P. From these results it would appear that the $40 \%$ PIP contribution in $A$. minutum cultured under replete $\mathrm{f} / 2$ nutrient conditions is not overestimated.

The "1 M HCl" method may overestimate PIP. We noted that the hydrolysis of labile organic $\mathrm{P}$, mainly nucleotidic $\mathrm{P}$, under the " $1 \mathrm{M} \mathrm{HCl}$ " conditions concerns only a very low percentage of TPP. Concerning polyphosphate, only 41 to $49 \%$ are hydrolysed. By subtraction, the rest, constituting the major part (51 to $59 \%$ ), is included in the POP pool. Thus the "1 $\mathrm{M} \mathrm{HCl}$ method underestimates polyphosphate P. Conversely, if the CWO method is used, 3 to $47 \%$ of polyphosphate $\mathrm{P}$ are included in the POP pool, thus the major part, 53 to $97 \%$ is in the PIP pool. In any case, polyphosphate P contributions to TPP in suspended matter are low in natural coastal plankton populations and sinking particles, $4-7 \%$ and $7 \%$, according to 
Miyata and Hattori (1986) and Diaz et al. (2008), respectively. Thus the "1 M HCl" method does not lead to a high overestimation of PIP.

Alternatively, the CWO method may overestimate POP. The study by Cade-Menun and Paytan (2010) showed phosphate as a major $P$ reserve in phytoplankton since it contributed to 59 to $98 \%$ of PIP and 33 to $79 \%$ of cellular P in numerous algal species (Table 5). Obviously, it depends on the species. In $S$. costatum and $H$. akashiwo, phosphate contribution to PIP reached $94 \%$ and 24 to $68 \%$ respectively (Miyata et al. 1986, Table 5). Therefore, unlike the widespread idea that polyphosphate is the major $P$ reserve in phytoplankton (Cembella et al., 1984; Orchard et al., 2010), phosphate could even be a dominant inorganic $\mathrm{P}$ form in microalgae. Taking these findings into account, the use of the CWO method may lead to an important contribution of intracellular algal phosphate within the POP pool. We tested the possibility that the simple immersion of filters in DIW may liberate a substantial quantity of phosphate by lysis of cells. We measured the phosphate concentration in $20 \mathrm{ml}$ DIW after a 3 hour immersion of filters from $A$. minutum cultures and Aulne estuary samples. A minimum of $7.3 \mathrm{pg} \mathrm{P}$ cell $^{-1}$ and $0.044 \mu \mathrm{M} \mathrm{P}$ as phosphate was extracted by this protocol in the algal and Aulne estuary samples, respectively, i.e. $42 \%$ and $7 \%$ of $\mathrm{P}$ extracted by the CWO method. Thus our CWO method obviously overestimated POP by including intracellular phosphate or particle-adsorbed phosphate. This can be corrected by an additional measurement of liberated phosphate as described above. Actually, when the CWO method is applied to estuarine samples (Figure 4), the evolution of PIP and POP concentrations in the salinity gradient is similar to that of the "1M HCl" method i.e. a decrease with increasing salinity in winter and a maximum in the low salinity $(5-10)$ part of estuaries in summer. But, especially in winter and at low salinity, the contribution of PIP to TPP is abnormally low while phosphate is mainly adsorbed on SPM in freshwaters and detrital and mineral SPM may dominate in these waters due to the low biological production.

Both methods tested in the present study are compromises. They didn't succeed in definitively separate PIP and POP. However, the use of the "1 M HCl" extraction method i.e. the PIP method of Aspila et al. (1976) seems to be the best compromise to estimate the contribution of each pool to TPP. It underestimates polyphosphate but includes intracellular phosphate which often seems to be the dominant inorganic pool in plankton. In addition it includes little organic P. Taking these findings into account, it also benefits from the fact that it is commonly used for PIP estimation and was evaluated elsewhere on geochemical inorganic P (Ruttenberg 1990, 1992). Analyses by ${ }^{31} \mathrm{P}-\mathrm{RMN}$ could be a complementary approach giving a more precise description of organic $\mathrm{P}$ forms even if this approach has its own limitations (weak sensitivity, problems linked to extraction for liquid ${ }^{31} \mathrm{P}-\mathrm{RMN}, \ldots$ ).

Phosphorus supply is increasingly recognized as a major driver of marine ecosystems (Dyhrman et al. 2007). River P, through its transport across estuaries, is the major source of $P$ to the oceans and is mainly associated with particles (Ruttenberg, 2003). The form by which $P$ reaches the coastal ocean is crucial to understand its influence on primary production, microbial diversity, and evaluate the eutrophication potential of $\mathrm{P}$ supply (large inputs of $\mathrm{P}$ or unbalanced $\mathrm{N}, \mathrm{P}, \mathrm{Si}$ inputs). Thus we need methods for the speciation of this particulate $\mathrm{P}$, firstly into inorganic and organic pools and ultimately to estimate the bioavailability potential of this pool to microbial dynamics of the coastal ocean.

\section{Conclusion}

By testing both pure organic and inorganic $P$ compounds and naturally combined $P$ compounds in phytoplankton and estuarine water samples, this study compares different 
methods for TPP measurement and for speciation into PIP and POP. The method of Solorzano and Sharp (1980) for TPP analysis is recommended compared with that of Aspila et al. (1976) as there is one step less (no final dilution step before phosphate quantification), the protocol is more explicit (use of $\mathrm{MgSO}_{4}$ ) and the results are the best. In fact, if Aspila et al. (1976) is applied as in the original protocol (no $\mathrm{MgSO}_{4}$ ), the results obtained are underestimated and highly variable. For PIP measurement, the Aspila method was tested for the first time for the interference of organic $P$ molecules. Only a very low percentage of organic $\mathrm{P}$, essentially nucleotidic $\mathrm{P}$, is included in the PIP pool. The alternative CWO method tested here to measure POP directly, succeeds in providing sufficient oxidation of organic $P$ compounds, except di and triphosphate nucleotides. The hydrolysis of inorganic $P$ compounds is actually reduced compared with other CWO methods. However, it still reaches a significant value. In addition, on reviewing the scarce phytoplankton $P$ composition literature, it appears that intracellular phosphate content may be high and may significantly contribute to the POP pool with this method. Finally the use of Aspila et al. (1976) for PIP seems to be the best compromise in estimating the contribution of PIP and POP to TPP, even if particulate polyphosphate is only partially hydrolysed. In any case, our findings show clear evidence of the necessity to fully describe the procedure when $\mathrm{P}$ speciation methods are used. Since the methods always turn out to be compromises, it is crucial for readers to know exactly which analytical protocol is used to assess the potential over/underestimations. This can lead to important consequences when comparing environmental studies.

\section{Acknowledgements}

This research was supported by the French EC2CO Moitem-Estuaires project ("Ecosphère Continentale et Côtière"). We wish to thank R. Kerouel for his technical advice and P. Bodenes for illustrations.

\section{References}

Aminot, A., Kérouel, R., Coverly, S.C., 2009. Nutrients in seawater using segmented flow analysis. In: Wurl, O. (Ed), Practical guidelines for the analysis of seawater. pp. 143-178

Aminot, A., Kérouel, R., 2007. Dosage automatique des nutriments dans les eaux marines: méthodes en flux continu. Ed. Ifremer, Méthodes d'analyse en milieu marin. 188 p.

Aminot, A., Kérouel, R., 2004. Mesures des concentrations en carbone, azote et phosphore organiques particulaires, in : Ifremer (Ed.), Hydrologie des écosystèmes marins. Paramètres et analyses. pp. 194-214.

Andrieux-Loyer, F., Philippon, X., Bally, G., Kerouel, R., Youenou, A., Le Grand, J., 2008. Phosphorus dynamics and bioavailability in sediments of the Penze' Estuary (NW France): in relation to annual P-fluxes and occurrences of Alexandrium minutum. Biogeochemistry 88, 213-231

Aspila, K.I., Agemian, H., Chau, A.S., 1976. A semi-automated method for the determination of inorganic, organic and total phosphate in sediments. Analyst 101, 187-197

Benitez-Nelson, C.R., O'Neill, L., Kolowith, L.C., Pellechia, P., Thunell, R., 2004. Phosphonates and particulate organic phosphorus cycling in an anoxic marine basin Limnology and Oceanography 49, 1593-1604 
Cade-Menun, B.J., Paytan, A., 2010. Nutrient temperature and light stress alter phosphorus and carbon forms in culture-grown algae. Marine Chemistry 121, 27-36

Cembella, A.D., Antia, N.J., Harrison, P.J., 1984. The utilization of inorganic and organic phosphorus compounds as nutrients by eukaryotic microalgae: a multidisciplinary perspective. Part 2. CRC Critical Reviews in Microbiology 11, 13-81

Conley, D.J., Smith, W.M., Cornwell, J.C., Fisher, T.R. 1995. Transformation of Particlebound Phosphorus at the Land-Sea interface. Estuarine, Coastal and Shelf Science 40, 161176

Deborde, J., Anschutz, P., Chaillou, G., Etcheber, H., Commarieu, M.V., Lecroart, P., Abril, G., 2007. The dynamics of phosphorus in turbid estuarine systems: Example of the Gironde estuary (France). Limnology and Oceanography 52, 862-872

Diaz, J., Ingall, E., Benitez-Nelson, C., Paterson, D., de Jonge, M.D., McNulty, I., Brandes, J.A., 2008. Marine polyphosphate: a key player in geologic phosphorus sequestration. Science 320, 652-655

Dyhrman, S.T., Ammerman, J.W., Van Mooy, B.A.S. 2007. Microbes and the Marine Phosphorus Cycle. Oceanography 20, 110-116

Fang, T.H., Chen, J.L., Huh, C.A., 2007. Sedimentary phosphorus species and sedimentation flux in the East China Sea. Continental Shelf Research 27, 1465-1476

Gleyzes, C., Tellier, S., Astruc, M., 2002. Fractionation studies of trace elements in contaminated soils and sediments: a review of sequential extraction procedures. Trends in Analytical Chemistry 21, 451-467

Guillard, R.R.L., Ryther, J.H., 1962. Studies of marine planktonic diatoms. I. Cyclotella nana Hustedt and Detonula confervacea Cleve. Canadian Journal of Microbiology 8, 229-239

Kérouel, R., Aminot, A., 1996. Model compounds for the determination of organic and total phosphorus dissolved in natural waters. Analytica Chimica Acta 318, 385-390

Koroleff, F., 1983. Determination of phosphorus. In: Grasshoff, K., Ehrhardt, M., Kremling, K. (Eds), Methods of Seawater Analysis. Verlag Chemie, Weinheim, 2nd ed., pp125-139

Loh, A. N., Bauer, J. E., 2000. Distribution, partitioning and fluxes of dissolved and particulate organic $\mathrm{C}, \mathrm{N}$ and $\mathrm{P}$ in the eastern North Pacific and Southern Oceans. Deep-Sea Research I 47, 2287-2316

Maher, W., Woo, L., 1998. Procedures for the storage and digestion of natural waters for the determination of filterable reactive phosphorus, total filterable phosphorus and total phosphorus. Analytica Chimica Acta 375, 5-47

Menzel, D.W., Corwin, N., 1965. The measurement of total phosphorus in seawater based on the liberation of organically bound fractions by persulfate oxidation. Limnology and Oceanography 10, 280-282

Meybeck, M., 1982. Carbon, nitrogen and phosphorus transport by world rivers. American Journal of Science 282, 401-450 
Miyata, K., Hattori, A., 1986. A simple fractionation method for determination of phosphorus components in phytoplankton: Application to natural populations of phytoplankton in summer surface waters of Tokyo bay. Journal of the Oceanographical Society of Japan 42, 255-265

Miyata, K., Hattori, A., Ohtsuki, A., 1986. Variation of cellular phosphorus composition of skeletoneme costatum and heterosigma akashiwo in chemostats. Marine Biology 93, 291297

Monaghan, E.J., Ruttenberg, K.C., 1999. Dissolved organic phosphorus in the coastal ocean: reassessment of available methods and seasonal phosphorus profiles from the Eel River Shelf Limnology and Oceanography 44(7), 1702-1714

Murphy, J., Riley, J.P., 1962. A modified single solution method for the determination of phosphate in natural waters. Analytica Chimica Acta 27, 31-36

Nemery, J., Garnier, J., 2007. Typical features of particulate phosphorus in the Seine estuary (France). Hydrobiologia 588, 271-290

Orchard, E.D., Benitez-Nelson, C.R., Pellechia, P.J., Lomas, M.W., Dyhrman, S.T., 2010. Polyphosphate in Trichodesmium from the low-phosphorus Sargasso Sea. Limnology and Oceanography 55(5), 2161-2169

Ormaza-Gonzalez, F.I., Statham, P.J., 1996. A comparison of methods for the determination of dissolved and particulate phosphorus in natural waters. Water Research 30(11), 27392747

Pujo-Pay, M., Raimbault, P., 1994. Improvement of the wet-oxidation procedure for simultaneous determination of particulate organic nitrogen and phosphorus collected on filters. Marine Ecology Progress Series 105, 203-207

Raimbault, P., Diaz, F., Pouvesle, W., Boudjellal, B., 1999. Simultaneous determination of particulate organic carbon, nitrogen and phosphorus collected on filters, using a semiautomatic wet-oxidation method. Marine Ecology Progress Series 180, 289-295.

Rhee, G.Y., 1973. A continuous culture study of phosphate uptake, growth rate and polyphosphate in Scenedesmus sp. Journal of Phycology 9, 495-506

Ruttenberg, K.C., 1990. Diagenesis and burial of phosphorus in marine sediments : implications for the marine phosphorus budget. Yale University. Ann Arbor : University Microfilm International. 375 p.

Ruttenberg, K.C., 1992. Development of a sequential extraction method for different forms of phosphorus in marine sediments. Limnology and Oceanography 37(7), 1460-1482

Ruttenberg, K.C., 2003. The global phosphorus cycle, in: Schlesinger, W.H. (ed), Treatise on geochemistry, Vol 8. Elsevier, pp. 585-643.

Ruttenberg, K.C., Ogawa, N.O., Tamburini, F., Briggs, R.A., Colasacco, N.D., Joyce, E., 2009. Improved, high-throughput approach for phosphorus speciation in natural sediments via the SEDEX sequential extraction method. Limnology and Oceanography 7, 319-333

Slomp, C. P, Malschaert, J. F. P., Van Raaphorst, W., 1998. The role of adsorption in sediment-water exchange of phosphate in North Sea continental margin sediments. Limnology and Oceanography 43(5), 832-846 
Solórzano, L. and Sharp, J. H., 1980. Determination of total dissolved phosphorus and particulate phosphorus in natural waters. Limnology and Oceanography 25, 754-758

Suzumura, M., Kokubun, H., Arata, N., 2004. Distribution and characteristics of suspended particulate matter in a heavily eutrophic estuary, Tokyo Bay, Japan. Marine Pollution Bulletin 49, 496-503

Suzumura, M., 2008. Persulfate chemical wet oxidation method for the determination of particulate phosphorus in comparison with a high-temperature dry combustion method. Limnology and Oceanography Methods 6, 619-629

Thompson, P.A., Oh, H.M., Rhee, G.Y., 1994. Storage of phosphorus in Nitrogen-fixing Anabaena flos-aquae (cyanophyceae). Journal of Phycology 30, 267-273

Thomson-Bulldis, A., Karl, D., 1998. Application of a novel method for phosphorus determinations in the oligotrophic North Pacific Ocean. Limnology and Oceanography 43, 1565-1577

Valderrama, J.C., 1981. The simultaneous analysis of total nitrogen and total phosphorus in natural waters. Marine Chemistry 10, 109-122

Van Der Zee, C., Chou, L., 2005. Seasonal cycling of phosphorus in the southern bight of the North Sea. Biogeosciences 2(1), 27-42

Van Der Zee, C., Roevros, N., Chou, L., 2007. Phosphorus speciation, transformation and retention in the Scheldt estuary (Belgium/The Netherlands) from the freshwater tidal limits to the North Sea. Marine Chemistry 106, 76-91

Worsfold, P.J., Monbet, P., Tappin, A.D., Fitzsimons, M.F., Stiles, D.A., McKelvie, I.D., 2008. Characterisation and quantification of organic phosphorus and organic nitrogen components in aquatic systems: A review. Analytica Chimica Acta 624(1), 37-58

Yoshimura, T., Nishioka, J., Saito, H., Takeda, S., Tsuda, A., Wells, M. L., 2007. Distributions of particulate and dissolved organic and inorganic phosphorus in North Pacific surface waters. Marine Chemistry 103, 112-121

Yuan, H., Song, J., Lin, I., Li, X., Zhang, Y., Xu S., 2009. Spatial distributions and seasonal variations of particulate phosphorus in the Jiaozhou Bay in North China. Acta Oceanologica Sinica 28(1), 99-108

Zwolsman, J.J.G., 1994. Seasonal variability and biogeochemistry of phosphorus in the Scheldt estuary, South-west Netherlands. Estuarine, Coastal and Shelf Science 39, 227-248 


\section{Figures}

Figure 1 : Diagram of analytical methods applied to samples.

\section{Sample on glass fiber filter or in $200 \mu \mathrm{l}$ solution}

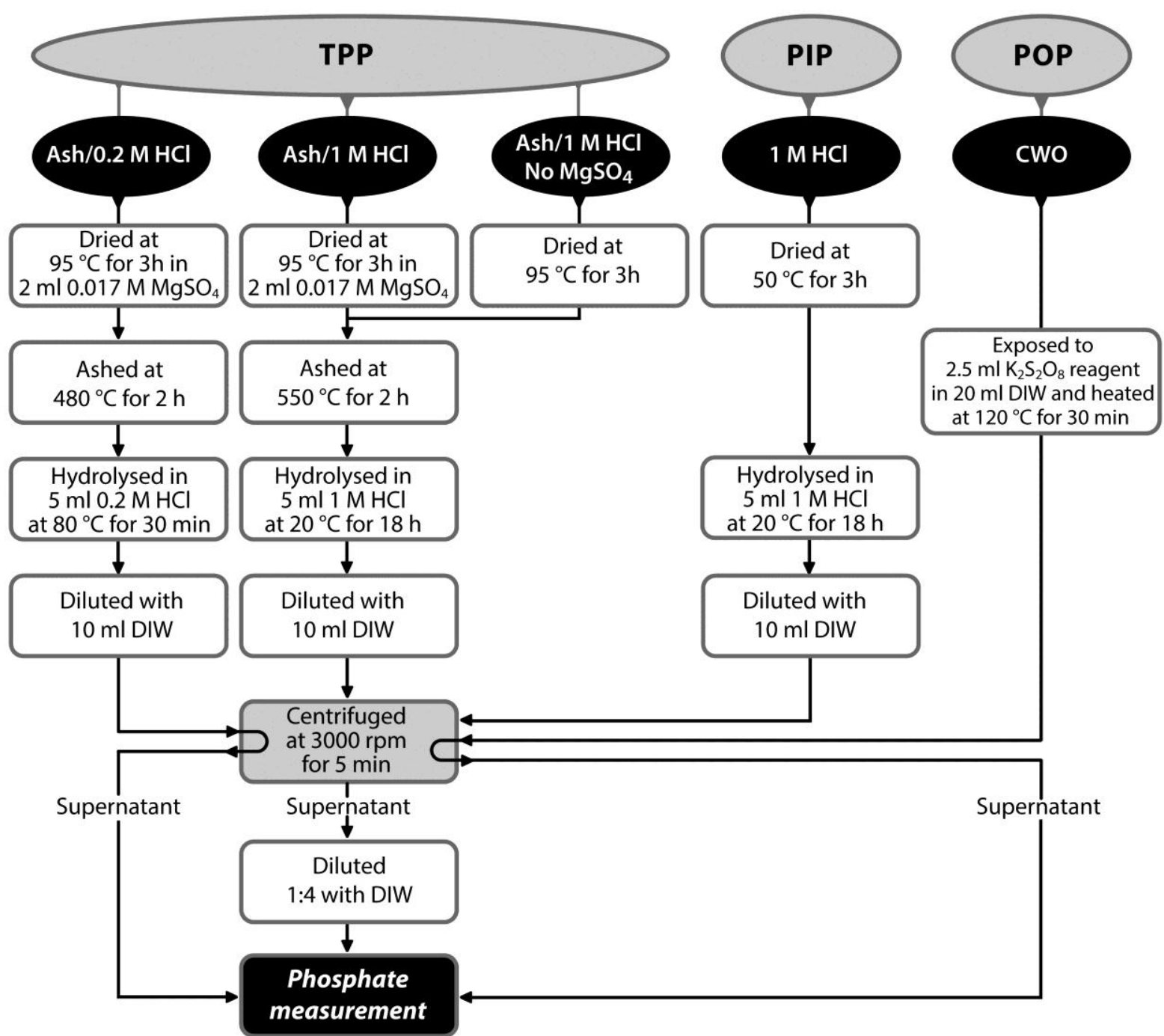


Figure 2 : Representation of inorganic and organic $\mathrm{P}$ constituting abiotic and biotic particles

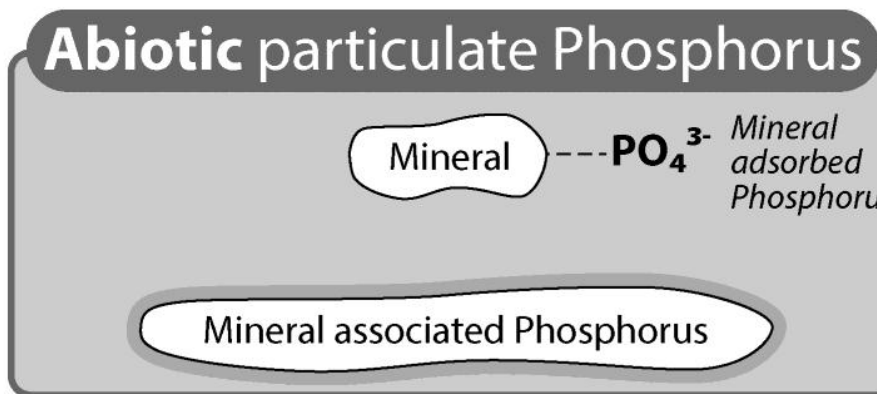

Biotic particulate Phosphorus

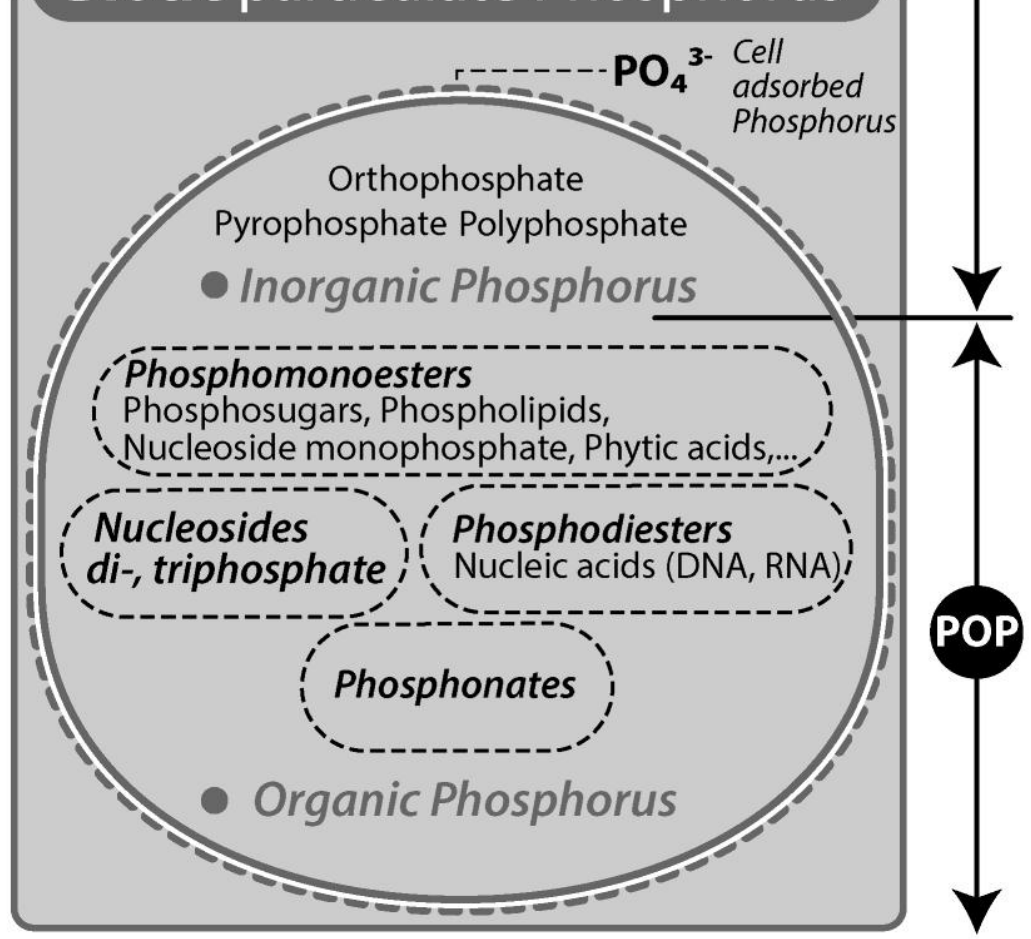


Figure 3 : Contribution of PIP and POP to TPP in Alexandrium minutum cultures and in the Aulne estuary. The methods used were " $1 \mathrm{M} \mathrm{HCl}$ " extraction method for PIP and calculation of POP as the difference between TPP and PIP, or CWO method for POP and calculation of PIP as the difference between TPP and POP.

$\square$ PIP $\square$ POP

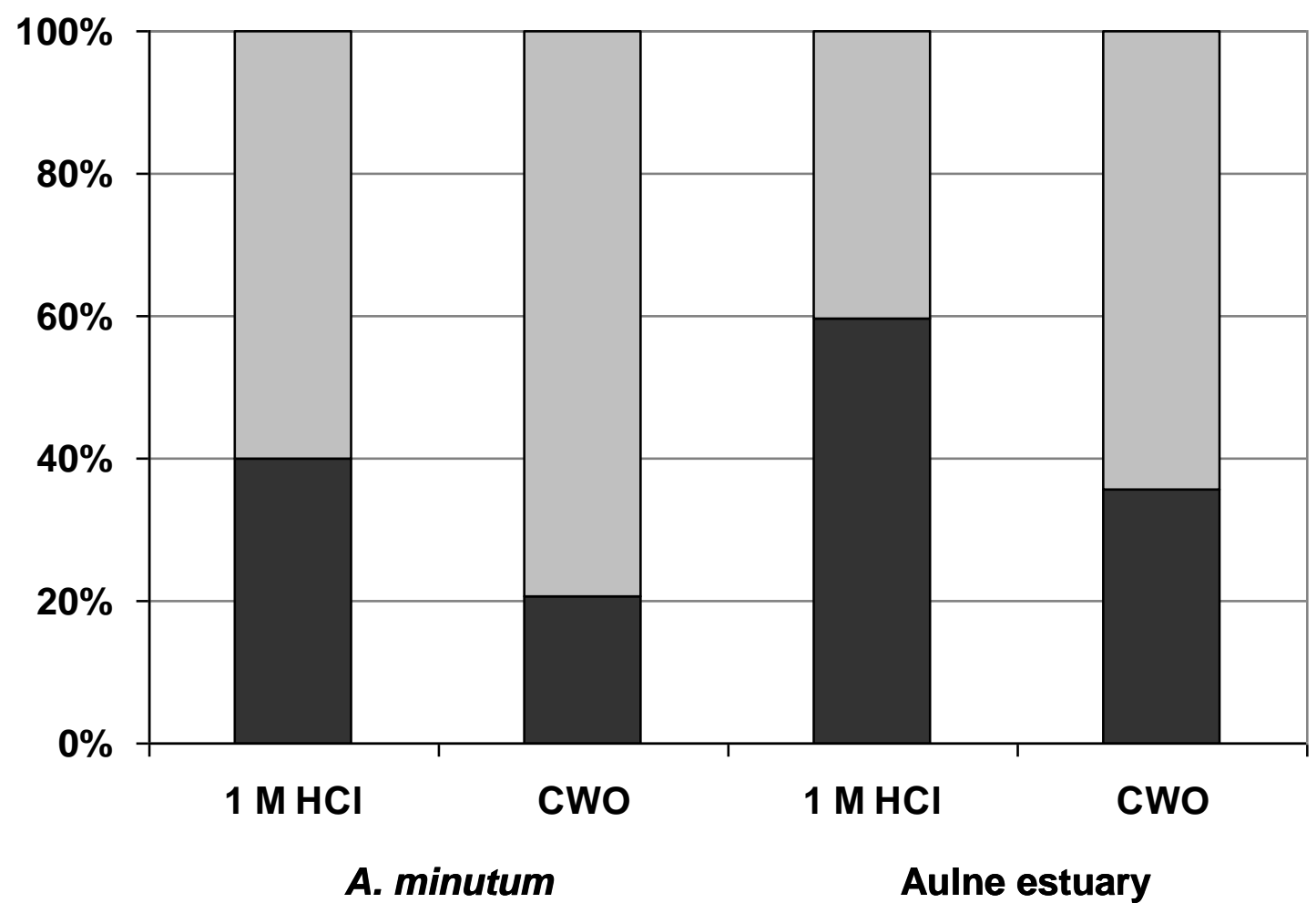


Figure 4 Concentration of PIP and POP $(\mu \mathrm{M})$ and contribution of PIP to TPP in the salinity gradient of the Aulne estuary in February and July 2009. The methods used were "1 M HCl" extraction method for PIP and calculation of POP as the difference between TPP and PIP (left), or CWO method for POP and calculation of PIP as the difference between TPP and POP (right).
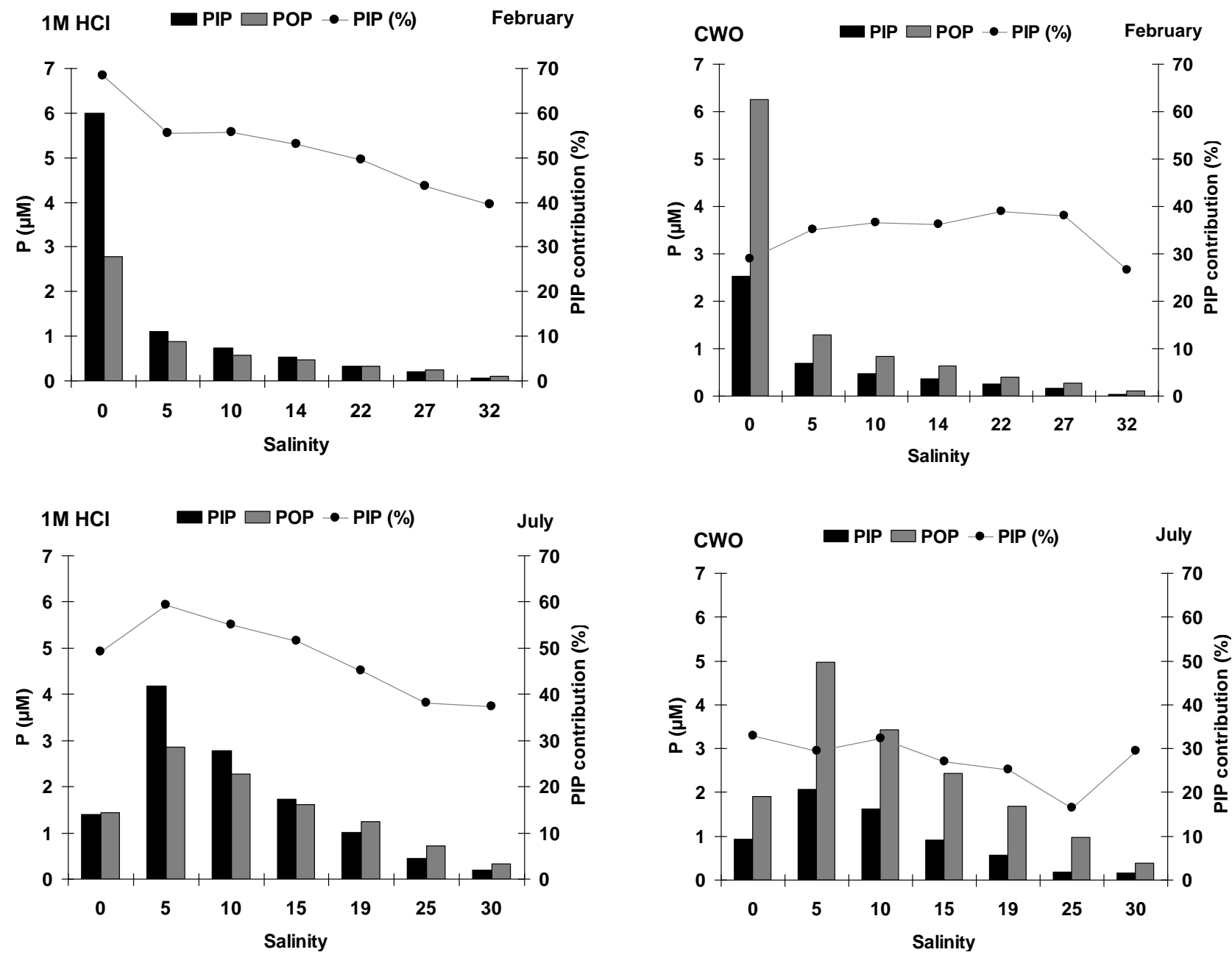


\section{Tables}

Table 1 Organic and inorganic $\mathrm{P}$ compounds used to test PP methods. Number of $\mathrm{P}$ atoms (nP) per molecule is indicated.

\begin{tabular}{|c|c|c|c|c|}
\hline Name of compound & Compound group & $P$ bonding & Abbreviation in text & $n \mathbf{P}$ \\
\hline 2-aminoethylphosphonic acid & Phosphonate & C-P & AEPA & 1 \\
\hline Riboflavin 5'-phosphate sodium salt hydrate & Phosphomonoester & C-O-P & RMP & 1 \\
\hline ß-glycerol phosphate disodium salt pentahydrate & Phosphomonoester & C-O-P & GP & 1 \\
\hline Phosphorylcholine chloride, calcium salt tetrahydrate & Phosphomonoester & C-O-P & PCC & 1 \\
\hline Phospho(enol)pyruvic acid trisodium salt hydrate & Phosphomonoester & C-O-P & PEPA & 1 \\
\hline D-Ribose-5-phosphate, disodium salt dihydrate & Phosphomonoester & C-O-P & $\mathrm{RP}$ & 1 \\
\hline D-Glucose-6-phosphate monosodium salt & Phosphomonoester & C-O-P & GluP & 1 \\
\hline Adenosine $5^{\prime}$-monophosphate disodium salt & Phosphomonoester & C-O-P & AMP & 1 \\
\hline Phytic acid sodium salt hydrate & Phosphomonoester & C-O-P & PA & 6 \\
\hline Deoxyribonucleic acid, sodium salt Type III & Phosphodiester & $\mathrm{C}-\mathrm{O}-\mathrm{P}-\mathrm{O}-\mathrm{C}$ & DNA & $\mathrm{n}$ \\
\hline Adenosine 5'-diphosphate, di(monocyclohexylammonium) salt & Nucleotide & C-O-P, P-O-P & $\mathrm{ADP}$ & 2 \\
\hline Adenosine 5 '-triphosphate, disodium salt hydrate & Nucleotide & C-O-P, P-O-P & ATP & 3 \\
\hline Sodium pyrophosphate decahydrate & Polyphosphate & Linear P-O-P & PP & 2 \\
\hline Tetrapolyphosphate hexa-ammonium salt & Polyphosphate & Linear P-O-P & TP & 4 \\
\hline Sodium polyphosphate crystal & Polyphosphate & Linear P-O-P & polyP-n & $\mathrm{n}$ \\
\hline Trisodium trimetaphosphate & Polyphosphate & Ring P-O-P & $\mathrm{MP}$ & 3 \\
\hline Sodium hexametaphosphate & Polyphosphate & Ring $\mathbf{P}-\mathbf{O}-\mathbf{P}$ & $\mathrm{HP}$ & 6 \\
\hline
\end{tabular}


Table 2 Mean \pm standard deviation (sample number) of blanks and recovery for $\mathrm{PO}_{4}$ solution calculated on the basis of the $\mathrm{PO}_{4}$ theoretical concentration corrected for manufacturer's purity. Reagent blanks include contamination from hydrolysis or oxidizing reagent $\left(\mathrm{MgSO}_{4}\right.$, $\mathrm{HCl}_{\text {, }}$ $\mathrm{K}_{2} \mathrm{~S}_{2} \mathrm{O}_{8}, \ldots$ ) and contamination from the reagent used for the final quantification of phosphate.

\begin{tabular}{|c|c|c|c|c|}
\hline \multirow{2}{*}{ Sample } & \multicolumn{2}{|c|}{ TPP } & POP & PIP \\
\cline { 2 - 5 } & Ash/0.2 M HCl & Ash/1 M HCl & CWO & $\mathbf{1 ~ M ~ H C l}$ \\
\hline DIW + Reagent Blanks $(\mu \mathrm{mol} / \mathrm{L})$ & $0.028 \pm 0.012(33)$ & $0.027 \pm 0.007(6)$ & $0.085 \pm 0.004(20)$ & $0.016 \pm 0.005(8)$ \\
\hline DIW + Reagent + GF/F Blanks $(\mu \mathrm{mol}$ per filter) & $0.001 \pm 0.0003(10)$ & $0.001 \pm 0.0008(10)$ & $0.004 \pm 0.0003(10)$ & - \\
\hline Recovery for $\mathrm{PO}_{4}$ solution $(\%)$ & $101.1 \pm 0.7(9)$ & $100.0 \pm 2.1(17)$ & $101.6 \pm 0.6(12)$ & $99.9 \pm 2.0(15)$ \\
\hline
\end{tabular}


Table 3 Response of $\mathrm{P}$ compounds as $\mathrm{PO}_{4}$ and normalized recovery using different methods. Values in brackets are standard deviation $(\mathrm{n}=3$ ). All results were expressed as percentage of the HTC/hydrolysis method of Solorzano and Sharp (1980). The response in $1 \mathrm{M} \mathrm{HCl}$ includes the responses as $\mathrm{PO}_{4}$. NT, not tested. ${ }^{* *}$ indicates value is highly significantly different from $\mathrm{PO}_{4}$ value $(p<0.001$, Mann and Whitney test).

\begin{tabular}{|c|c|c|c|c|c|c|c|c|}
\hline \multirow[t]{2}{*}{$P$ bonding } & \multirow[t]{2}{*}{ Abb. } & \multirow[t]{2}{*}{$n \mathbf{P}$} & \multirow[t]{2}{*}{$\mathrm{PO}_{4}$} & \multicolumn{3}{|l|}{ TPP } & \multirow{2}{*}{$\begin{array}{l}\text { POP } \\
\text { CWO }\end{array}$} & \multirow{2}{*}{$\begin{array}{l}\text { PIP } \\
1 \mathrm{M} \mathrm{HCl}\end{array}$} \\
\hline & & & & Ash/0.2 M HCl & Ash/1 M HCl & Ash/1 M HCl No $\mathrm{MgSO}_{4}$ & & \\
\hline C-P & AEPA & 1 & $0.0(0.0)$ & $100(1.0)$ & $99(1.2)$ & 33 (11.0) & $102(1.0)$ & $1.0(1.2)^{(*)}$ \\
\hline C-O-P & RMP & 1 & $4.6(0.1)$ & $100(0.5)$ & $100(1.5)$ & $42(3.2)$ & $102(0.4)$ & $4.2(1.5)$ \\
\hline C-O-P & GP & 1 & $1.5(0.0)$ & $100(0.2)$ & $97(2.6)$ & $38(1.4)$ & $100(0.6)$ & $1.8(0.9)$ \\
\hline C-O-P & PCC & 1 & $0.1(0.1)$ & $100(0.7)$ & $98(2.9)$ & $65(0.7)$ & $100(0.1)$ & $1.4(0.9)^{(*)}$ \\
\hline C-O-P & PEPA & 1 & $0.5(0.1)$ & $100(0.3)$ & $98(3.3)$ & NT & $100(0.6)$ & $9.9(2.2)^{(*)}$ \\
\hline C-O-P & $\mathrm{RP}$ & 1 & $2.2(0.0)$ & $100(0.2)$ & $99(0.5)$ & NT & $101(0.5)$ & $2.9(0.1)^{(*)}$ \\
\hline C-O-P & GluP & 1 & $0.5(0.1)$ & $100(0.4)$ & $98(1.6)$ & $44(2.1)$ & $102(0.3)$ & $0.9(0.2)^{(*)}$ \\
\hline C-O-P & AMP & 1 & $0.3(0.0)$ & $100(0.5)$ & $97(2.4)$ & NT & $100(0.4)$ & $0.5(0.2)^{(*)}$ \\
\hline C-O-P & PA & 6 & $4.2(0.2)$ & $100(0.1)$ & $99(4.7)$ & NT & $101(0.2)$ & $6.3(0.2)^{(*)}$ \\
\hline C-O-P-O-C & DNA & $\mathrm{n}$ & $0.3(0.1)$ & $100(0.4)$ & $99(0.3)$ & NT & $103(0.0)$ & $0.0(0.4)$ \\
\hline C-O-P, P-O-P & ADP & 2 & $0.1(0.1)$ & $100(0.1)$ & $100(0.1)$ & NT & $26(0.6)$ & $9.9(0.3)^{(*)}$ \\
\hline C-O-P, P-O-P & ATP & 3 & $0.2(0.0)$ & $100(0.3)$ & $97(0.6)$ & $33(2.5)$ & $29(0.7)$ & $23.6(0.4)^{(*)}$ \\
\hline Linear $\mathbf{P}-\mathrm{O}-\mathrm{P}$ & $\mathrm{PP}$ & 2 & $0.5(0.0)$ & $100(0.1)$ & $102(0.3)$ & NT & $25(0.3)$ & $46.1(0.4)^{(*)}$ \\
\hline Linear P-O-P & $\mathrm{TP}$ & 4 & $2.9(0.1)$ & $100(0.4)$ & $99(0.5)$ & $41(3.5)$ & $47(0.6)$ & $41.3(0.1)^{(*)}$ \\
\hline Linear P-O-P & polyP-n & $\mathrm{n}$ & $9.9(0.1)$ & $100(0.4)$ & $102(0.2)$ & NT & $28(0.1)$ & $48.1(0.2)^{(*)}$ \\
\hline Ring $\mathbf{P}-\mathbf{O}-\mathbf{P}$ & $\mathrm{MP}$ & 3 & $1.4(0.2)$ & $100(0.0)$ & $102(0.2)$ & NT & $3(0.1)$ & $48.0(0.4)^{(*)}$ \\
\hline Ring P-O-P & $\mathrm{HP}$ & 6 & $1.5(0.0)$ & $100(0.1)$ & $101(0.2)$ & NT & $29(0.1)$ & $48.6(0.1)^{(*)}$ \\
\hline
\end{tabular}

(*) Indicates value is highly significantly different from $\mathrm{PO}_{4}$ value $(p<0.001$, Mann and Whitney test). 
Table 4 Mean \pm standard deviation $(n=5)$ of particulate $\mathrm{P}$ obtained by different methods from cultures of Alexandrium minutum (pgP/cell) and the Aulne estuary $(\mu \mathrm{mol} / \mathrm{l})$.

\begin{tabular}{|c|c|c|c|c|c|}
\hline \multirow{2}{*}{ Sample } & \multicolumn{3}{|c|}{ TPP } & POP & PIP \\
\cline { 2 - 6 } & Ash/0.2 M HCl & Ash/1 M HCl & Ash/1 M HCl No MgSO & CWO & 1 M HCl \\
\hline A. minutum & $21.8 \pm 0.4$ & $21.1 \pm 0.2$ & $19.9 \pm 0.5$ & $17.3 \pm 0.2$ & $8.7 \pm 0.3$ \\
\hline Aulne estuary & $0.98 \pm 0.01$ & $0.93 \pm 0.03$ & $0.94 \pm 0.01$ & $0.63 \pm 0.01$ & $0.59 \pm 0.02$ \\
\hline
\end{tabular}


Table 5 Review of PIP and phosphate contribution to TPP and PIP in phytoplankton samples.

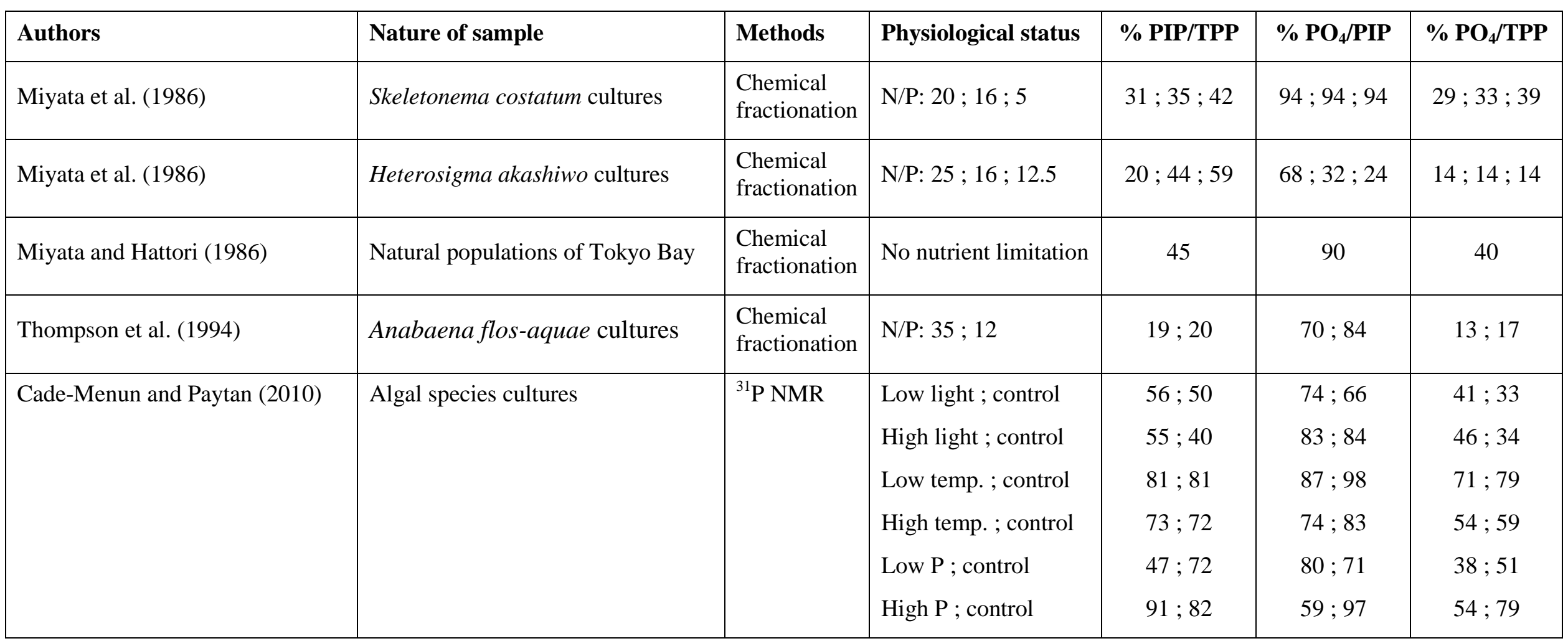

